\title{
Key features of nano-emulsion formation by the phase inversion temperature (PIT) method
}

Jin Feng ${ }^{1}$, Jordi Esquena ${ }^{2}$, Carlos Rodriguez-Abreu ${ }^{2 *}$, and Conxita Solans ${ }^{2}$

${ }^{1}$ Inner Mongolia Vocational College of Chemical Engineering, Hohhot, China

${ }^{2}$ Institut de Química Avançada de Catalunya, Consejo Superior de Investigaciones Científicas

(IQAC-CSIC) and CIBER en Bioingeniería, Biomateriales y Nanomedicina, (CIBER-BBN),

Jordi-Girona 18-26, 08034-Barcelona, Spain

*Corresponding author, carlos.rodriguez@iqac.csic.es 


\title{
Key features of nano-emulsion formation by the phase inversion temperature (PIT) method
}

\begin{abstract}
Nano-emulsion formation by the phase inversion temperature (PIT) method is reviewed. Characteristic features of low-energy emulsification are first summarized and then follows a description of the main characteristics of the PIT emulsification method. The main focus is on the relation between phase behaviour and nano-emulsion formation. Emphasis is put on the key role of phase transitions involving equilibrium phases such as lamellar liquid crystalline and/or bicontinuous microemulsion phases to obtain nano-emulsions with minimum and controlled droplet size.
\end{abstract}

Keywords: nano-emulsions, PIT, phase behavior, non-ionic surfactants

\section{Introduction}

Nano-emulsions are submicron-size emulsions with droplet diameters typically in the range 20-200 $\mathrm{nm}{ }^{1}$, although a size range cannot be exactly established as there is no sharp change in the physicochemical properties of emulsions when passing from micrometer to nanometer range. These colloidal systems have been designated in the literature with different terminology, such as miniemulsions ${ }^{2-4}$, ultrafine emulsions ${ }^{5}$, submicron emulsions ${ }^{6}$ or nanoemulsions ${ }^{7,8}$. This last term has been increasingly adopted because it indicates unequivocally the size range and it is concise. Due to the misunderstandings that they are still prevailing in the literature, in spite of the efforts ${ }^{9,10}$ to clarify the difference between nanoemulsions and microemulsions (which are not emulsions as they are thermodynamically stable systems), the authors prefer the notation "nano-emulsion" to emphasize their emulsion nature. 
The small droplet size confers nano-emulsions characteristic properties such as high surface area/volume ratio, stability towards sedimentation or creaming and transparent/translucent aspect. These properties are very relevant for a wide range of applications and consequently they are receiving increasing attention.

High surface area/volume ratio is important in applications where interfacial properties are decisive (e.g. their use as solubilization or reaction media) ${ }^{6,11,12}$. Although nanoemulsions are stable against creaming or sedimentation (because the gravity forces are considerably reduced and the Brownian motion overcomes gravity) they may undergo other breakdown mechanisms (flocculation, coalescence and/or Ostwald ripening). It has been shown and it is widely accepted that nano-emulsion main destabilization process is Ostwald ripening ${ }^{13,14}$ which consists on the diffusion through the continuous phase of molecules of the disperse phase from small to big droplets, as a consequence of their different Laplace pressure. Nevertheless, nano-emulsions with high kinetic stability can be formulated by a proper choice of system components. In addition to the other characteristic properties, the visual transparent aspect of nano-emulsions confers them an esthetical character of interest in cosmetic, personal care, food (e. g. beverage) and pharmaceutical applications ${ }^{15-17}$

As nano-emulsions are non-equilibrium systems, an energy input is required for their formation and properties such as droplet size and stability depend on the preparation method $^{18,19}$. Nano-emulsions, as all types of emulsions, can be prepared by dispersion and by condensation methods, generally known as high- and low-energy methods, respectively ${ }^{18-21}$. The energy input of the former is external and nano-emulsion formation is generally achieved using mechanical devices (e.g. high-pressure homogenizers, ultrasound generators) able to produce intense disruptive forces. In these methods, generally the higher the energy input the smaller the droplet size; above certain energy input the 
size tends to level off and does not decrease anymore. Only a small amount (as low as $0.1 \%$ ) of the energy supplied is used for emulsification as the rest is dissipated as heat ${ }^{14}$. Therefore, high-energy methods are cost-inefficient for producing nano-emulsions. In contrast, low-energy methods take advantage of the internal energy of the system to achieve emulsification. The resulting droplet size is independent on the external energy applied as it depends on the physicochemical properties of the system. Moreover, simple equipment (i.e. of relatively low cost) is needed and emulsification can be carried out in mild conditions with high yield and reasonable process time. Therefore, low-energy emulsification can be considered more cost-efficient than high-energy methods and this is the main reason why they are focussing considerable attention from a practical viewpoint ${ }^{1,22,23}$.

This review deals with nano-emulsion formation by the phase inversion temperature (PIT) method. Characteristic features of low-energy emulsification and the PIT method are first summarized. It follows a discussion on the relationship between phase behaviour and nano-emulsion formation, exemplified by a description of a water/mixed pure nonionic surfactants/oil system.

\section{Low-energy emulsification}

Depending on whether emulsification is triggered by a diffusion process ${ }^{24,25}$ or by inversion of the spontaneous curvature of the surfactant during emulsification ${ }^{26,27}$, low-energy emulsification methods are classified as "self-emulsification" or "phase inversion", respectively. For estimation of the spontaneous curvature, we refer to the seminal paper by Strey $^{28}$ and those that followed. In self-emulsification (also referred to as spontaneous-emulsification) energy is released by diluting with the continuous phase (typically 
water) the rest of components (typically a mixture of oil and a solvent miscible with both oil and water). During the dilution process leading to oil-in-water $(\mathrm{O} / \mathrm{W})$ nanoemulsions, diffusion of water-miscible components (solvent, surfactant and/or cosurfactant) from the oil mixture into the aqueous phase is produced resulting in a metastable

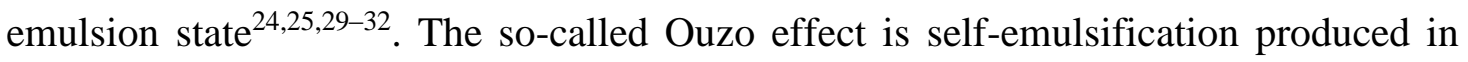
systems with no surfactant molecules. A drawback is that nanosized droplets can only be obtained at very high solvent/oil ratios (i.e. low oil volume fractions). In phase inversion methods, energy is released when phase transitions occur due to changes in the surfactant spontaneous curvature during emulsification which inverts from negative (W/O emulsions) to positive (O/W emulsions) or viceversa (W/O emulsions) ${ }^{26,27}$. Inversion processes can be triggered by changing temperature (keeping composition constant) ${ }^{26}$ or composition (at constant temperature) ${ }^{27}$, the so-called phase inversion temperature (PIT) and phase inversion composition (PIC) methods, respectively.

Low-energy methods were described long ago and have been used industrially. Selfemulsification was discovered by $\mathrm{J}$. Gad in $1879^{33}$ and the possible mechanisms were discussed more than eighty years later by J. T. Davies and E. K. Rideal ${ }^{34}$. The Phase Inversion Temperature (PIT) emulsification method based on the changes of the lipophilic-hydrophilic properties of some type of surfactants with temperature was introduced by K. Shinoda and H. Saito in $1968^{35}$. T. J. Lin et al. in $1975^{27}$ described an emulsification method, designated years later as PIC method, consisting in the addition of water to a mixture of surfactant and oil. Interesting contributions to the different lowenergy emulsification methods were produced in the 1980's and 1990's. C. A. Miller ${ }^{24}$ introduced the "diffusion path theory" for self-emulsification, H. Sagitani ${ }^{5}$ described an emulsification method combining heating and dilution to obtain finely dispersed 
droplets , J. L. Salager et $\mathrm{al}^{36}$ defined two kinds of emulsion inversion, transitional (induced by intermolecular interaction changes) and catastrophic (induced by changes in the water/oil ratio). T. Förster et $\mathrm{al}^{37}$ obtained fine emulsions of the order of $100 \mathrm{~nm}$ (i.e. nano-emulsions) by heating the sample above PIT and then cooling it down. They pointed out that transition through a bicontinuous microemulsion and/or lamellar liquid crystalline phase was required. Salager's group ${ }^{38}$ described miniemulsion formation by transitional inversion and stated that a microemulsion phase was required to obtain nanosized droplets. The key role of bicontinuous and/or lamellar structures in emulsification were evidenced in earlier reports ${ }^{39-41}$. In the last two decades, great research effort has been devoted to clarify the mechanisms of nano-emulsion formation ${ }^{42-51,52-58}$ as well as on the study of their properties and applications ${ }^{59-65,66-70}$ which has been reflected in diverse reviews ${ }^{1,14-17,71-79}$.

\section{Characteristics of the Phase Inversion Temperature (PIT) emulsification}

PIT emulsification is based on the changes in the surfactant spontaneous curvature triggered by temperature. Therefore, it can be only applied to systems with surfactants sensitive to temperature changes, namely polyoxyethylene-type nonionic surfactants ${ }^{26}$. The hydrophilic-lipophilic properties of these surfactants vary with temperature as it induces changes in the hydration of the poly(oxyethylene) chains ${ }^{35,40}$. At low temperatures, polyoxyethylene-type nonionic surfactants have a large positive spontaneous curvature and form direct type structures while at high temperatures, the spontaneous curvature becomes negative forming reverse type structures. At intermediate temperatures, the so-called hydrophilic-lipophilic balance (HLB) temperature ${ }^{26,40}$, the spontaneous curvature becomes zero or almost zero and structures such as bicontinuous microemusions and lamellar liquid crystalline phases are formed (see Figure 1). At the HLB temperature, extremely low interfacial tensions (of the order $10^{-2}-10^{-3} \mathrm{mNm}^{-1}$ ) are 
achieved, which favour emulsification. However, coalescence is very fast. Therefore, emulsions are very unstable at the HLB temperature. Shinoda ${ }^{26}$ showed that emulsions with small droplet size, narrow size distribution and high kinetic stability could be obtained by rapidly cooling or heating samples prepared at or close to the HLB temperature. If cooling is too slow, fast coalescence avoid the formation of nanoemulsions. During the cooling process, inversion from reverse type, W/O structures to $\mathrm{O} / \mathrm{W}$ structures takes place, while for the heating process the reverse is true. Knowledge of the HLB temperature (i.e. phase inversion temperature or PIT) of the emulsion system is a requirement to apply this emulsification method. This parameter can be obtained by phase diagram determinations and also by electrical conductivity measurements. Although the PIT emulsification method is simple to perform it may not be suitable when using thermo-sensitive molecules.

To achieve optimum emulsification knowledge on the phase behaviour of emulsion components is of utmost interest in low-energy emulsification ${ }^{1,5}$

\section{Relation between phase behaviour and nano-emulsion formation}

Studies on the phase behaviour of water/poly(oxyethylene) nonionic surfactant/oil systems as a function of temperature have been crucial to elucidate the mechanisms of nanoemulsion formation by the PIT method ${ }^{43,44,46,47,48}$. The so called fish diagram ${ }^{28}$, i.e. the section of the phase diagram prism at constant water/oil ratio (Figure 1, left) is very useful to get insight on those mechanisms. An example of such a diagram for a ternary system water/non-ionic surfactant/oil is shown in Figure $2{ }^{80}$. Herewith, poly(oxyethylene) nonionic surfactants are abbreviated as $\mathrm{CiEj}$, where $\mathrm{i}$ and $\mathrm{j}$ are the length of the alkyl and poly(oxyethylene) chains, respectively. For the case of a single surfactant, such as the one depicted in Figure 2, the fish diagram is approximately symmetric above and below the PIT, i.e. if an isotherm at PIT is taken as the axis of symmetry. In practice, however, many 
products contain a mixture of surfactants, and the fish diagram get distorted or asymmetric as a result of changes in the composition of the interfacial layer with total surfactant concentration. The characteristic features of this type of systems are exemplified by the phase behaviour of the water/ $\mathrm{C}_{16} \mathrm{E}_{4}+\mathrm{C}_{12} \mathrm{E}_{6} /$ decane system, which is the result of adding a more lipophilic surfactant $\left(\mathrm{C}_{16} \mathrm{E}_{4}\right)$ to the system corresponding to Figure 2. The phase diagram of the water/ $\mathrm{C}_{16} \mathrm{E}_{4}+\mathrm{C}_{12} \mathrm{E}_{6} /$ decane system is plotted in Figure 3 as a function of temperature and total surfactant concentration $\left(\mathrm{S}_{\mathrm{T}}\right)$ at a constant water/decane $(\mathrm{W} / \mathrm{O})$ weight ratio of $80 / 20$. This ratio is more relevant to nano-emulsion formation as compared to that of Figure 2, which is the typical used for fish diagrams. In Figure 3 only the threeliquid phase region $(\mathrm{W}+\mathrm{D}+\mathrm{O})$, the microemulsion phase region $(\mathrm{D})$ and the multiphase region with liquid crystalline phase present (LC) are shown. The structure of the liquid crystalline phase is of the lamellar type $(\mathrm{L} \alpha)$. The intersection of the microemulsion phase region, $\mathrm{D}$, with the three-phase region, $\mathrm{W}+\mathrm{D}+\mathrm{O}$, indicates the lowest concentration of total surfactant to form a microemulsion, which in this system is produced at a $\mathrm{S}_{\mathrm{T}}$ value of $4 \mathrm{wt} \%$ and at $29^{\circ} \mathrm{C}$. It should be noted that the three-phase region is shifted towards higher temperatures as $S_{T}$ value is decreased. This is a characteristic behavior of mixed (technical) grade surfactant systems which is due to the different partition of the surfactant molecules between the bulk phases and the interface with the change in surfactant concentration. The PIT at each surfactant concentration falls in the middle of the $(\mathrm{W}+\mathrm{D}+\mathrm{O})$ region for the lower surfactant concentration and in the middle of the $\mathrm{D}+\mathrm{LC}$ region for higher surfactant. As shown in Figure 3, the system evolves from a W/O to an $\mathrm{O} / \mathrm{W}$ structure by decreasing the temperature. The transition takes place through the threephase region $(\mathrm{W}+\mathrm{D}+\mathrm{O})$ at low surfactant concentrations $(4.4 \mathrm{wt} \%$ in this system), while at higher surfactant concentrations transition takes place through either $D$ or $D+L_{\alpha}$ phases. 
An early report ${ }^{39}$ on the influence of the phases present in the system on droplet size of emulsions obtained by the PIT method showed that starting emulsification in the three phase region $(\mathrm{W}+\mathrm{D}+\mathrm{O})$ and rapidly cooling at a temperature far below the PIT resulted in emulsions with small droplet size. However, emulsions with smaller droplet size and narrower size distribution were obtained when emulsification was started from the single D-phase (bicontinuous microemulsion phase) and brought to the same low temperature. From these results, it was concluded that emulsification in the bicontinuous microemulsion D phase is the mechanism responsible for achieving small droplet size when emulsifying by the PIT method ${ }^{39}$. It could be argued that the increase in surfactant concentration is mainly responsible for the decrease in droplet size. Figure 4 shows droplet size of emulsions of the water/ $\mathrm{C}_{16} \mathrm{E}_{4}+\mathrm{C}_{12} \mathrm{E}_{6} /$ decane system obtained by the PIT method as a function of the total surfactant concentration. Emulsification started at the three-phase region $(\mathrm{W}+\mathrm{D}+\mathrm{O})$ and finalized in the two phase $\left(\mathrm{W}_{\mathrm{m}}+\mathrm{O}\right)$ region where the $\mathrm{O} / \mathrm{W}$ structure is formed. A sharp decrease in droplet size from $180 \mathrm{~nm}$ to $80 \mathrm{~nm}$, for $2 \mathrm{wt} \%$ and $4 \mathrm{wt} \%$ surfactant, respectively, is observed. Similar results were obtained by Izquierdo et al. 43,46,47 using systems with technical grade nonionic surfactants in which nano-emulsion droplet size and polydispersity decreased with the increase in surfactant concentration. The smallest sizes were obtained when emulsification started in a single D microemulsion phase or in a two-phase region (D+ $\mathrm{L}_{\alpha}$ ) consisting of $\mathrm{D}$ and lamellar liquid crystalline $\left(\mathrm{L}_{\alpha}\right)$ phases.

The remaining question was if the decrease in droplet size with the increase in surfactant concentration was merely related to surfactant concentration or to the increase in volume fraction of the $\mathrm{D}$ microemulsion phase. The changes in droplet size keeping the surfactant concentration constant are very illustrative. Figure 5 shows the phase diagram of the water/ $\mathrm{C}_{16} \mathrm{E}_{4}+\mathrm{C}_{12} \mathrm{E}_{6} /$ decane system at constant water/decane $(\mathrm{W} / \mathrm{O})$ weight ratio of $80 / 20$ and 
total surfactant concentration of $5 \%$, as a function of temperature and surfactant mixing ratio $\left(\mathrm{W}_{1}\right)$. A single-phase region (I) consisting of a shear-birefringent microemulsion exists at $\mathrm{W}_{1}$ between 0.15 and 0.5 in the temperature range between $45^{\circ} \mathrm{C}$ and $25^{\circ} \mathrm{C}$. $\mathrm{A}$ region containing liquid crystalline (LC) phases is observed at $\mathrm{W}_{1}$ between 0.15 and 0.5 in the temperature range between $47^{\circ} \mathrm{C}$ and $28^{\circ} \mathrm{C}$. It should be noted that the one phase (I) and LC-present phase regions are shifted towards higher temperatures as $\mathrm{W}_{1}$ is decreased as a consequence of to the presence of more hydrophilic surfactant $\left(\mathrm{C}_{12} \mathrm{E}_{6}\right)$. Figure 6 shows droplet size of nano-emulsions obtained by cooling samples from the PIT to $25^{\circ} \mathrm{C}$ (indicated by arrows in Figure 5) as a function of $\mathrm{W}_{1}$. Emulsification started in the microemulsion phase region for samples with $\mathrm{W}_{1}$ values between 0.2 and 0.4 , and finalized, for all $\mathrm{W}_{1}$ values, at the two-phase $\left(\mathrm{W}_{\mathrm{m}}+\mathrm{O}\right)$ region. Droplet size decreases from $100 \mathrm{~nm}$ $\left(\mathrm{W}_{1}=0.1\right)$ to $70 \mathrm{~nm}\left(\mathrm{~W}_{1}=0.2-0.4\right)$. These results clearly show that emulsification from the bicontinuous microemulsion phase accounts for the effectiveness of the emulsification process.

The results of the research dealing with the relation between phase behavior and nanoemulsion formation ${ }^{39,42,44}$ evidenced the importance of phases with mean zero spontaneous curvature (e.g. bicontinuous microemulsions and lamellar liquid crystalline phases) to obtain very small droplet size ${ }^{81}$. It was also inferred that minimum droplet size was achieved when emulsification started from one single (bicontinuous microemulsion or lamellar liquid crystalline) phase. However, D. Morales at al. ${ }^{44,48}$ showed that minimum droplet size can be achieved starting emulsification not only from a single-bicontinuous microemulsion phase but also from compositions displaying multi-phase equilibria, provided that all the surfactant and oil coexist in the same phase, (e.g. phase equilibria consisting of a bicontinuous microemulsion and excess water phase). This finding allowed 
to conclude that droplet formation is controlled by the structure of the bicontinuous microemulsion and the excess water acts as mere dilution medium. The proposed mechanism of $\mathrm{O} / \mathrm{W}$ nano-emulsion formation by the PIT method was thermal disruption of the bicontinuous microemulsion (or lamellar liquid crystalline) phase by the decrease in temperature which produces a change in curvature of the surfactant monolayer giving rise to oil droplet formation.

More recent contributions to the mechanisms of nano-emulsion formation are those of $\mathrm{K}$. Roger et al. ${ }^{56,77}$. They observed that a few degrees below the PIT, where a bicontinuous microemulsion coexists with excess oil, and under gentle shear, a homogeneous phase (“Clearing Boundary"), consisting of an $\mathrm{O} / \mathrm{W}$ microemulsion, appeared as a metastable structure. By cooling from this "Clearing Boundary" (sub-PIT method), nano-emulsions with the same size as that obtained by cooling from or above the PIT were obtained (Figure 7). These results supported a mechanism of nano-emulsion formation through non-equilibrium self-assembly by disruption of the bicontinuous microemulsion coexisting with excess oil and water (Figure 8). It was concluded that this "Clearing Boundary" (or "Access State") acts as template and determines nano-emulsion droplet size. Strictly, the Sub-PIT method should not be regarded as an inversion method since at the initial state $(\mathrm{O} / \mathrm{W}$ microemulsion) the surfactant preferred curvature at the interface is of the same sign as that at the final state (O/W nano-emulsion).

It was reported ${ }^{56,77}$ that this sub-PIT emulsification can provide very similar results, in terms of particle size distribution, as "cross-PIT" emulsification in which PIT is crossed during the temperature change. These results confirmed that the nanostructure of the last phase crossed during emulsification greatly determines the final properties of the formed nano-emulsion. Moreover, it was also confirmed that the droplet size is directly controlled by the oil/surfactant ratio. The emulsification process is highly efficient in the sense that 
most of the surfactant molecules are adsorbed on droplets, and consequently, the size of droplets is determined by the total interfacial area that can be covered by surfactant molecules. This allows a prediction of the final droplet size, as a function of composition and other known parameters such as the surfactant area per molecule ${ }^{77}$.

In the recent years, there have been numerous publications on nano-emulsions, most of them dealing with formulation with different kinds of oils and on applications. However, contributions on the mechanisms of nano-emulsion formation by low-energy methods are missing. With the present knowledge it can be stated that transition through selfassembled structures with an average zero curvature (e.g. bicontinuous microemulsions or lamellar liquid crystalline phases) is essential to obtain nanosized droplets. It has also been demonstrated that nano-emulsion droplet size is controlled by the structure of the bicontinuous microemulsion or lamellar liquid crystalline phase present during the emulsification process.

\section{Conclusions}

The Phase Inversion Temperature (PIT) emulsification method is based on the changes in lipophilic-hydrophilic properties of polyoxyethylene-type nonionic surfactants with temperature. Oil-in water $(\mathrm{O} / \mathrm{W})$ nano-emulsions are obtained by rapidly cooling samples prepared at or close to the PIT. During the cooling process inversion from reverse type water-in-oil (W/O), structures and/or transitions trough self-assembled structures with an average zero curvature (e.g. bicontinuous microemulsions or lamellar liquid crystalline phases) to oil-in water $(\mathrm{O} / \mathrm{W})$ structures takes place. These self-assembled structures with average zero curvature play a key role not only for the formation of nanosized droplets but also controlling the size of the resulting nano-emulsions. It has been shown that minimum droplet size is achieved when all the surfactant and oil are in the same phase when starting emulsification. Although the PIT emulsification method is simple to 
perform it can be only applied to systems with surfactants sensitive to temperature changes, namely polyoxyethylene-type nonionic surfactants and it may not be suitable when using thermo-sensitive molecules.

\section{Acknowledgments}

The authors are grateful to the Agencia Estatal de Investigación (AEI) and Fondo Europeo de Desarrollo Regional (FEDER) for funding (Project CTQ2017-84998-P)

\section{References}

(1) Solans, C.; Solé, I. Nano-Emulsions: Formation by Low-Energy Methods. Curr. Opin. Colloid Interface Sci. 2012, 17 (5), 246-254. https://doi.org/10.1016/j.cocis.2012.07.003.

(2) J. Ugelstad, M. S. El-Aasser, J. W. V. Emulsion Polymerization: Initiation of Polymerization in Monomer Droplets. J. Polym Sci Polym Lett 1973, 11, 503513. https://doi.org/10.1002/pol.1973.130110803.

(3) El-Aasser, M. S.; Lack, C. D.; Choi, Y. T.; Min, T. I.; Vanderhoff, J. W.; Fowkes, F. M. Interfacial Aspects of Miniemulsions and Miniemulsion Polymers. Colloids and Surfaces 1984, 12 (C), 79-97. https://doi.org/10.1016/01666622(84)80091-8.

(4) Antonietti, M.; Landfester, K. Polyreactions in Miniemulsions. Prog. Polym. Sci. 2002, 27 (4), 689-757. https://doi.org/10.1016/S0079-6700(01)00051-X.

(5) Sagitani, H. Making Homogeneous and Fine Droplet O/W Emulsions Using Nonionic Surfactants. J. Am. Oil Chem. Soc. 1981, 58 (6), 738-743. https://doi.org/10.1007/BF02899466.

(6) Amselem, S.; Friedman, D. Submicron Emulsions as Drug Carriers for Topical Administration. In Submicron emulsions in drug targeting and delivery; Benita, S., Ed.; Harwood Academic Publishers: Amsterdam, 1998; pp 153-173.

(7) Nakajima, H.; Tomomasa, S.; Okabe, M. Preparation of Nano-Emulsions. In Proceedings of First World Emulsion Conference; Paris, 1993.

(8) Nakajima, H. Microemulsions in Cosmetics. In Industrial Applications of Microemulsions; Solans C, K. H., Ed.; Marcel Dekker: New York, 1997; pp 175197.

(9) Anton, N.; Vandamme, T. F. Nano-Emulsions and Micro-Emulsions: Clarifications of the Critical Differences. Pharm. Res. 2011, 28 (5), 978-985. https://doi.org/10.1007/s11095-010-0309-1.

(10) McClements, D. J. Nanoemulsions versus Microemulsions: Terminology, Differences, and Similarities. Soft Matter 2012, 8 (6), 1719-1729. https://doi.org/10.1039/c2sm06903b. 
(11) McClements, D. J. Nanoemulsion-Based Oral Delivery Systems for Lipophilic Bioactive Components: Nutraceuticals and Pharmaceuticals. Ther. Deliv. 2013, 4 (7), 841-857. https://doi.org/10.4155/tde.13.46.

(12) Muñoz-Espí, R.; Álvarez-Bermúdez, O. Application of Nanoemulsions in the Synthesis of Nanoparticles. In Nanoemulsions.Formulation, Applications, and Characterization; McClements, D. J., Jafari, S. M., Eds.; London, 2018; pp 477515.

(13) Taylor, P. Ostwald Ripening in Emulsions. Adv. Colloid Interface Sci. 1998, 75 (2), 107-163. https://doi.org/10.1016/S0001-8686(98)00035-9.

(14) Tadros, T.; Izquierdo, P.; Esquena, J.; Solans, C. Formation and Stability of Nano-Emulsions. Adv. Colloid Interface Sci. 2004, 108-109, 303-318. https://doi.org/10.1016/j.cis.2003.10.023.

(15) Sonneville-Aubrun, O.; Yukuyama, M. N.; Pizzino, A. Application of Nanoemulsions in Cosmetics. In Nanoemulsions.Formulation, Applications, and Characterization; McClements, D. J., Jafari, S. M., Eds.; Academic Press: London, 2018; pp 435-475.

(16) Donsì, F. Application of Nanoemulsions in Foods. In Nanoemulsions.Formulation, Applications, and Characterization; McClements, D. J., Jafari, S. M., Eds.; Academic Press: London, 2018; pp 349-377.

(17) Sánchez-López, E.; Guerra, M.; Dias-Ferreira, J.; Lopez-Machado, A.; Ettcheto, M.; Cano, A.; Espina, M.; Camins, A.; Garcia, M. L.; Souto, E. B. Current Applications of Nanoemulsions in Cancer Therapeutics. Nanomaterials 2019, 9 (6). https://doi.org/10.3390/nano9060821.

(18) Walstra, P. Formation of Emulsions. In Encyclopedia of Emulsion Technology; Becher, P., Ed.; Marcel Dekker: New York, 1983; pp 57-127.

(19) Gopal, E. S. R. Principles of Emulsion Formation. In Emulsion Science; Sherman, P., Ed.; Academic Press: London, 1968; pp 1-75.

(20) Solans, C.; Izquierdo, P.; Nolla, J.; Azemar, N.; Garcia-Celma, M. J. NanoEmulsions. Curr. Opin. Colloid Interface Sci. 2005, 10 (3-4), 102-110. https://doi.org/10.1016/j.cocis.2005.06.004.

(21) Sagitani, H. Phase-Inversion and D-Phase Emulsification. In Organized Solutions; Friberg, S. E., Lindman, B., Eds.; Marcel Dekker: New York, 1992; pp 259-271.

(22) Solans, C.; García-Celma, M. J. Microemulsions and Nano-Emulsions for Cosmetic Applications. In Cosmetic Science and Technology: Theoretical Principles and Applications; Sakamoto, K., Lochhead, R., Maibach, H., Yamashita, Y., Eds.; Elsevier: Cambridge, 2017; pp 507-551.

(23) Guha, I. F.; Anand, S.; Varanasi, K. K. Creating Nanoscale Emulsions Using Condensation. Nat. Commun. 2017, 8 (1), 1-6. https://doi.org/10.1038/s41467017-01420-8.

(24) Miller, C. A. Spontaneous Emulsification Produced by Diffusion - A Review. Colloids and Surfaces 1988, 29 (1), 89-102. https://doi.org/10.1016/01666622(88)80173-2.

(25) Miller, C. Spontaneous Emulsification: Recent Developments with Emphasis on 
Self-Emulsification. In Emulsions and Emulsion Stability; Sjöblom, J., Ed.; Taylor \& Francis: Boca Raton, 2006; pp 107-126.

(26) Shinoda, K.; Saito, H. The Stability of O/W Type Emulsions as Functions of Temperature and the HLB of Emulsifiers: The Emulsification by PIT-Method. $J$. Colloid Interface Sci. 1969, 30 (2), 258-263. https://doi.org/10.1016/S00219797(69)80012-3.

(27) Lin, T.J.; Kurihara, H.; Ohta, H. Effects of Phase Inversion and Surfactant Location on the Formation of OVW Emulsions. J. Soc.Cosmet. Chem 1975, 26 (3), 121-139.

(28) Strey, R. Microemulsion Microstructure and Interfacial Curvature. Colloid Polym. Sci. 1994, 272 (8), 1005-1019. https://doi.org/10.1007/BF00658900.

(29) Bouchemal, K.; Briançon, S.; Perrier, E.; Fessi, H. Nano-Emulsion Formulation Using Spontaneous Emulsification: Solvent, Oil and Surfactant Optimisation. Int. J. Pharm. 2004, 280 (1-2), 241-251. https://doi.org/10.1016/j.ijpharm.2004.05.016.

(30) Vitale, S. A.; Katz, J. L. Liquid Droplet Dispersions Formed by Homogeneous Liquid-Liquid Nucleation: "The Ouzo Effect." Langmuir 2003, 19 (10), 41054110. https://doi.org/10.1021/la026842o.

(31) Ganachaud, F.; Katz, J. L. Nanoparticles and Nanocapsules Created Using the Ouzo Effect: Spontaneous Emulsification as an Alternative to Ultrasonic and High-Shear Devices. ChemPhysChem 2005, 6 (2), 209-216. https://doi.org/10.1002/cphc.200400527.

(32) Solans, C.; Morales, D.; Homs, M. Spontaneous Emulsification. Curr. Opin. Colloid Interface Sci. 2016, 22, 88-93. https://doi.org/10.1016/j.cocis.2016.03.002.

(33) Gad, J. Zur Lehre von Der Fettresorption. Arch Anat Physiol 1878, 181-192.

(34) Davies, J. T.; Rideal, E. K. Interfacial Phenomena, 2nd edition; Academic Press, 1963.

(35) Shinoda, K.; Saito, H. The Effect of Temperature on the Phase Equilibria and the Types of Dispersions of the Ternary System Composed of Water, Cyclohexane, and Nonionic Surfactant. J. Colloid Interface Sci. 1968, 26 (1), 70-74. https://doi.org/10.1016/0021-9797(68)90273-7.

(36) Salager, J. L.; Minana-Perez, M.; Pdrez-Sanchez, M.; Ramirez-Gouveia, M.; Rojas, C. I. Surfactant-Oil-Water Systems near the Affinity Inversion Part III: The Two Kinds of Emulsion Inversion. J. Dispers. Sci. Technol. 1983, 4 (3), 313-329. https://doi.org/10.1080/01932698308943373.

(37) Förster, T.; Schambil, F.; von Rybinski, W. Production of Fine Disperse and Long-Term Stable Oil-in-Water Emulsions by the Phase Inversion Temperature Method. J. Dispers. Sci. Technol. 1992, 13 (2), 183-193. https://doi.org/10.1080/01932699208943306.

(38) Miñana-Perez, M.; Gutron, C.; Zundel, C.; Anderez, J. M.; Salager, J. L. Miniemulsion Formation by Transitional Inversion. J. Dispers. Sci. Technol. 1999, 20 (3), 893-905. https://doi.org/10.1080/01932699908943826.

(39) Friberg, S.; Solans, C. Emulsification and the HLB-Temperature. J. Colloid 
Interface Sci. 1978, 66 (2), 367-368. https://doi.org/10.1016/00219797(78)90319-3.

(40) Shinoda, K.; Kunieda, H. Phase Properties of Emulsions: PIT and HLB. In Encyclopedia of emulsion technology; Becher, P., Ed.; Marcel Dekker: New York, 1983; pp 337-367.

(41) Kunieda, H.; Shinoda, K. Evaluation of the Hydrophile-Lipophile Balance ( HLB ) of Nonionic Surfactants. 1985, 107 (1).

(42) Forgiarini, A.; Esquena, J.; González, C.; Solans, C. Formation of NanoEmulsions by Low-Energy Emulsification Methods at Constant Temperature. Langmuir 2001, 17 (7), 2076-2083. https://doi.org/10.1021/la001362n.

(43) Izquierdo, P.; Esquena, J.; Tadros, T. F.; Dederen, C.; Garcia, M. J.; Azemar, N.; Solans, C. Formation and Stability of Nano-Emulsions Prepared Using the Phase Inversion Temperature Method. Langmuir 2002, 18 (1), 26-30. https://doi.org/10.1021/la010808c.

(44) Morales, D.; Gutiérrez, J. M.; García-Celma, M. J.; Solans, Y. C. A Study of the Relation between Bicontinuous Microemulsions and Oil/Water Nano-Emulsion Formation. Langmuir 2003, 19 (18), 7196-7200. https://doi.org/10.1021/la0300737.

(45) Fernandez, P.; André, V.; Rieger, J.; Kühnle, A. Nano-Emulsion Formation by Emulsion Phase Inversion. Colloids Surfaces A Physicochem. Eng. Asp. 2004, 251 (1-3), 53-58. https://doi.org/10.1016/j.colsurfa.2004.09.029.

(46) Izquierdo, P.; Esquena, J.; Tadros, T. F.; Dederen, J. C.; Feng, J.; Garcia-Celma, M. J.; Azemar, N.; Solans, C. Phase Behavior and Nano-Emulsion Formation by the Phase Inversion Temperature Method. Langmuir 2004, 20 (16), 6594-6598. https://doi.org/10.1021/la049566h.

(47) Izquierdo, P.; Feng, J.; Esquena, J.; Tadros, T. F.; Dederen, J. C.; Garcia, M. J.; Azemar, N.; Solans, C. The Influence of Surfactant Mixing Ratio on NanoEmulsion Formation by the Pit Method. J. Colloid Interface Sci. 2005, 285 (1), 388-394. https://doi.org/10.1016/j.jcis.2004.10.047.

(48) Morales, D.; Solans, C.; Gutiérrez, J. M.; Garcia-Celma, M. J.; Olsson, U. Oil/Water Droplet Formation by Temperature Change in the Water/ C16E6/Mineral Oil System. Langmuir 2006, 22 (7), 3014-3020. https://doi.org/10.1021/la052324c.

(49) Sajjadi, S. Nanoemulsion Formation by Phase Inversion Emulsification: On the Nature of Inversion. Langmuir 2006, 22 (13), 5597-5603. https://doi.org/10.1021/la060043e.

(50) Sonneville-Aubrun, O.; Babayan, D.; Bordeaux, D.; Lindner, P.; Rata, G.; Cabane, B. Phase Transition Pathways for the Production of 100 Nm Oil-inWater Emulsions. Phys. Chem. Chem. Phys. 2009, 11 (1), 101-110. https://doi.org/10.1039/b813502a.

(51) Wang, L.; Tabor, R.; Eastoe, J.; Li, X.; Heenan, R. K.; Dong, J. Formation and Stability of Nanoemulsions with Mixed Ionic-Nonionic Surfactants. Phys. Chem. Chem. Phys. 2009, 11 (42), 9772. https://doi.org/10.1039/b912460h.

(52) Roger, K.; Cabane, B.; Olsson, U. Formation of 10-100 Nm Size-Controlled Emulsions through a Sub-PIT Cycle. Langmuir 2010, 26 (6), 3860-3867. 
https://doi.org/10.1021/la903401g.

(53) Rao, J.; McClements, D. J. Stabilization of Phase Inversion Temperature Nanoemulsions by Surfactant Displacement. J. Agric. Food Chem. 2010, 58 (11), 7059-7066. https://doi.org/10.1021/jf100990r.

(54) Roger, K.; Cabane, B.; Olsson, U. Emulsification through Surfactant Hydration: The PIC Process Revisited. Langmuir 2011, 27 (2), 604-611. https://doi.org/10.1021/la1042603.

(55) Heunemann, P.; Prévost, S.; Grillo, I.; Marino, C. M.; Meyer, J.; Gradzielski, M. Formation and Structure of Slightly Anionically Charged Nanoemulsions Obtained by the Phase Inversion Concentration (PIC) Method. Soft Matter 2011, 7 (12), 5697-5710. https://doi.org/10.1039/c0sm01556c.

(56) Roger, K.; Olsson, U.; Zackrisson-Oskolkova, M.; Lindner, P.; Cabane, B. Superswollen Microemulsions Stabilized by Shear and Trapped by a Temperature Quench. Langmuir 2011, 27 (17), 10447-10454. https://doi.org/10.1021/la201685x.

(57) Anton, N.; Saulnier, P. Adhesive Water-in-Oil Nano-Emulsions Generated by the Phase Inversion Temperature Method. Soft Matter 2013, 9 (28), 6465-6474. https://doi.org/10.1039/c3sm51064f.

(58) Nazarzadeh, E.; Anthonypillai, T.; Sajjadi, S. On the Growth Mechanisms of Nanoemulsions. J. Colloid Interface Sci. 2013, 397, 154-162. https://doi.org/10.1016/j.jcis.2012.12.018.

(59) Wang, L.; Dong, J.; Chen, J.; Eastoe, J.; Li, X. Design and Optimization of a New Self-Nanoemulsifying Drug Delivery System. J. Colloid Interface Sci. 2009, 330 (2), 443-448. https://doi.org/10.1016/j.jcis.2008.10.077.

(60) Aubry, J.; Ganachaud, F.; Addad, J.-P. C.; Cabane, B. Nanoprecipitation of Polymethylmethacrylate by Solvent Shifting: 1. Boundaries. Langmuir 2009, 25 (4), 1970-1979. https://doi.org/10.1021/la803000e.

(61) Beck-Broichsitter, M.; Rytting, E.; Lebhardt, T.; Wang, X.; Kissel, T. Preparation of Nanoparticles by Solvent Displacement for Drug Delivery: A Shift in the "Ouzo Region" upon Drug Loading. Eur. J. Pharm. Sci. 2010, 41 (2), 244-253. https://doi.org/10.1016/j.ejps.2010.06.007.

(62) Vandamme, T. F.; Anton, N. Low-Energy Nanoemulsification to Design Veterinary Controlled Drug Delivery Devices. Int. J. Nanomedicine 2010, 5 (1), 867-873. https://doi.org/10.2147/IJN.S13273.

(63) Anton, N.; Mojzisova, H.; Porcher, E.; Benoit, J.-P.; Saulnier, P. Reverse Micelle-Loaded Lipid Nano-Emulsions: New Technology for NanoEncapsulation of Hydrophilic Materials. Int. J. Pharm. 2010, 398 (1-2), 204209. https://doi.org/10.1016/j.ijpharm.2010.07.039.

(64) Henry, J. V. L.; Fryer, P. J.; Frith, W. J.; Norton, I. T. The Influence of Phospholipids and Food Proteins on the Size and Stability of Model Sub-Micron Emulsions. Food Hydrocoll. 2010, 24 (1), 66-71. https://doi.org/10.1016/j.foodhyd.2009.08.006.

(65) Calderó, G.; García-Celma, M. J.; Solans, C. Formation of Polymeric NanoEmulsions by a Low-Energy Method and Their Use for Nanoparticle Preparation. J. Colloid Interface Sci. 2011, 353 (2), 406-411. 
https://doi.org/10.1016/j.jcis.2010.09.073.

(66) Rao, J.; McClements, D. J. Formation of Flavor Oil Microemulsions, Nanoemulsions and Emulsions: Influence of Composition and Preparation Method. J. Agric. Food Chem. 2011, 59 (9), 5026-5035. https://doi.org/10.1021/jf200094m.

(67) Lucas, P.; Vaysse, M.; Aubry, J.; Mariot, D.; Sonnier, R.; Ganachaud, F. Finest Nanocomposite Films from Carbon Nanotube-Loaded Poly(Methyl Methacrylate) Nanoparticles Obtained by the Ouzo Effect. Soft Matter 2011, 7 (12), 5528-5531. https://doi.org/10.1039/c1sm05609c.

(68) Ragupathy, L.; Ziener, U.; Robert, G.; Landfester, K. Grafting Polyacrylates on Natural Rubber Latex by Miniemulsion Polymerization. Colloid Polym. Sci. 2011, 289 (3), 229-235. https://doi.org/10.1007/s00396-010-2360-1.

(69) MacHado, A. H. E.; Lundberg, D.; Ribeiro, A. J.; Veiga, F. J.; Lindman, B.; Miguel, M. G.; Olsson, U. Preparation of Calcium Alginate Nanoparticles Using Water-in-Oil (W/O) Nanoemulsions. Langmuir 2012, 28 (9), 4131-4141. https://doi.org/10.1021/la204944j.

(70) Fornaguera, C.; Dols-Perez, A.; Calderó, G.; García-Celma, M. J.; Camarasa, J.; Solans, C. PLGA Nanoparticles Prepared by Nano-Emulsion Templating Using Low-Energy Methods as Efficient Nanocarriers for Drug Delivery across the Blood-Brain Barrier. J. Control. Release 2015, 211, 134-143. https://doi.org/10.1016/j.jconrel.2015.06.002.

(71) Anton, N.; Benoit, J. P.; Saulnier, P. Design and Production of Nanoparticles Formulated from Nano-Emulsion Templates-A Review. J. Control. Release 2008, 128 (3), 185-199. https://doi.org/10.1016/j.jconrel.2008.02.007.

(72) Date, A. A.; Desai, N.; Dixit, R.; Nagarsenker, M. Self-Nanoemulsifying Drug Delivery Systems: Formulation Insights, Applications and Advances. Nanomedicine 2010, 5 (10), 1595-1616. https://doi.org/10.2217/nnm.10.126.

(73) Silva, H. D.; Cerqueira, M. A.; Vicente, A. A. Nanoemulsions for Food Applications: Development and Characterization. Food Bioprocess Technol. 2012, 5 (3), 854-867. https://doi.org/10.1007/s11947-011-0683-7.

(74) Maali, A.; Mosavian, M. T. H. Preparation and Application of Nanoemulsions in the Last Decade (2000-2010). J. Dispers. Sci. Technol. 2013, 34 (1), 92-105. https://doi.org/10.1080/01932691.2011.648498.

(75) Muñoz-Espí, R.; Weiss, C. K.; Landfester, K. Inorganic Nanoparticles Prepared in Miniemulsion. Curr. Opin. Colloid Interface Sci. 2012, 17 (4), 212-224. https://doi.org/10.1016/j.cocis.2012.04.002.

(76) Gupta, A.; Eral, H. B.; Hatton, T. A.; Doyle, P. S. Nanoemulsions: Formation, Properties and Applications. Soft Matter 2016, 12 (11), 2826-2841. https://doi.org/10.1039/c5sm02958a.

(77) Roger, K. Nanoemulsification in the Vicinity of Phase Inversion: Disruption of Bicontinuous Structures in Oil/Surfactant/Water Systems. Curr. Opin. Colloid Interface Sci. 2016, 25, 120-128. https://doi.org/10.1016/j.cocis.2016.09.015.

(78) Montes de Oca-Ávalos, J. M.; Candal, R. J.; Herrera, M. L. Nanoemulsions: Stability and Physical Properties. Curr. Opin. Food Sci. 2017, 16, 1-6. https://doi.org/10.1016/j.cofs.2017.06.003. 
(79) Espitia, P. J. P.; Fuenmayor, C. A.; Otoni, C. G. Nanoemulsions: Synthesis, Characterization, and Application in Bio-Based Active Food Packaging. Compr. Rev. Food Sci. Food Saf. 2019, 18 (1), 264-285. https://doi.org/10.1111/15414337.12405.

(80) Aramaki, K.; Hayashi, T.; Katsuragi, T.; Ishitobi, M.; Kunieda, H. Effect of Adding an Amphiphilic Solubilization Improver, Sucrose Distearate, on the Solubilization Capacity of Nonionic Microemulsions. J. Colloid Interface Sci. 2001, 236 (1), 14-19. https://doi.org/10.1006/jcis.2000.7366.

(81) Rodríguez-Abreu, C.; Vila, A. Nano-Droplet Systems by Surfactant SelfAssembly and Applications in the Pharmaceutical Industry. Curr. Top. Med. Chem. 2014, 14 (6), 747-765. https://doi.org/10.2174/1568026614666140118221658.

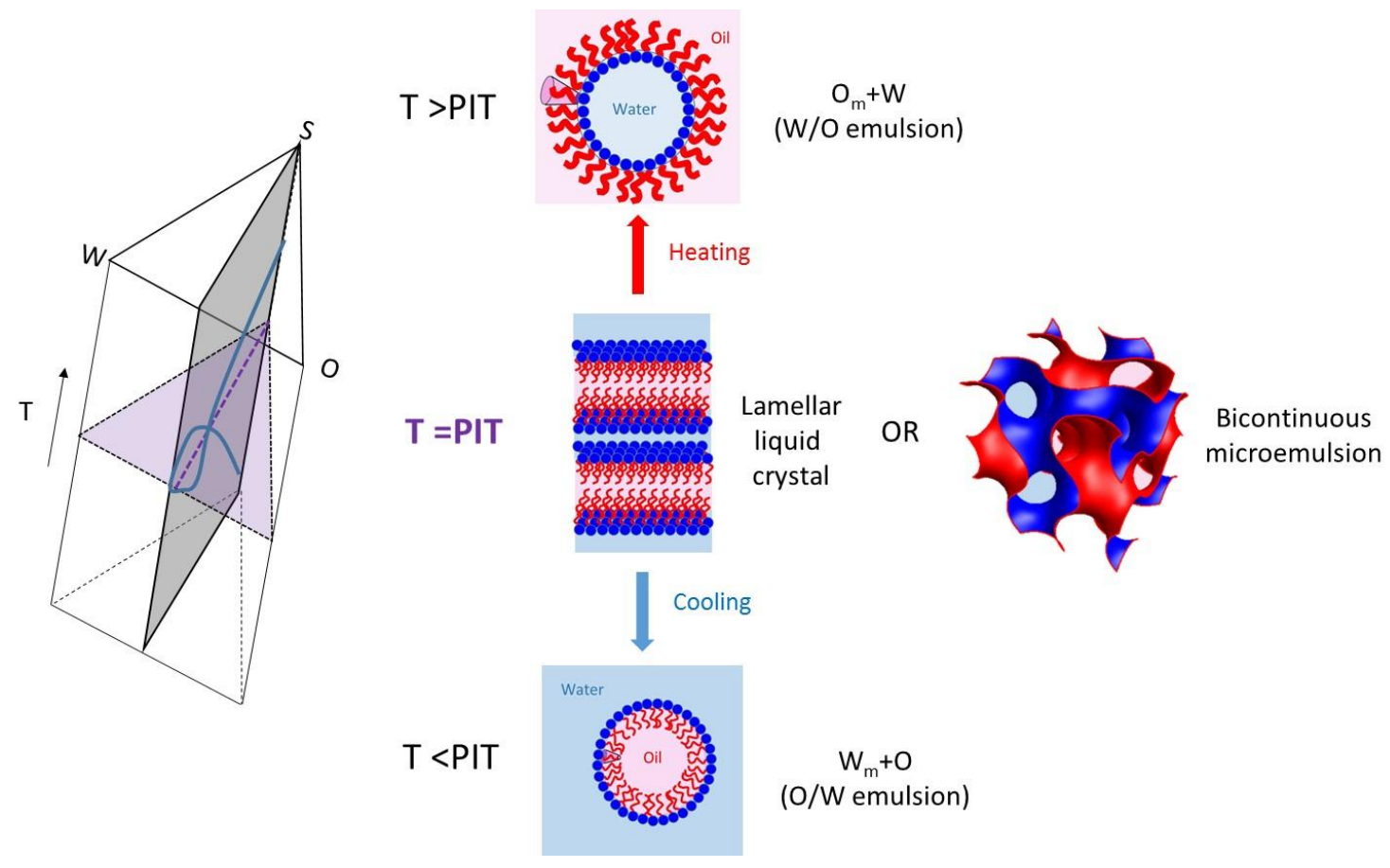

Figure 1: Scheme of the changes in the surfactant layer curvature with temperature in non-ionic surfactant/oil/water systems. The phase diagram prism is shown on the left with the section at constant water/oil ratio (the so called fish diagram) 


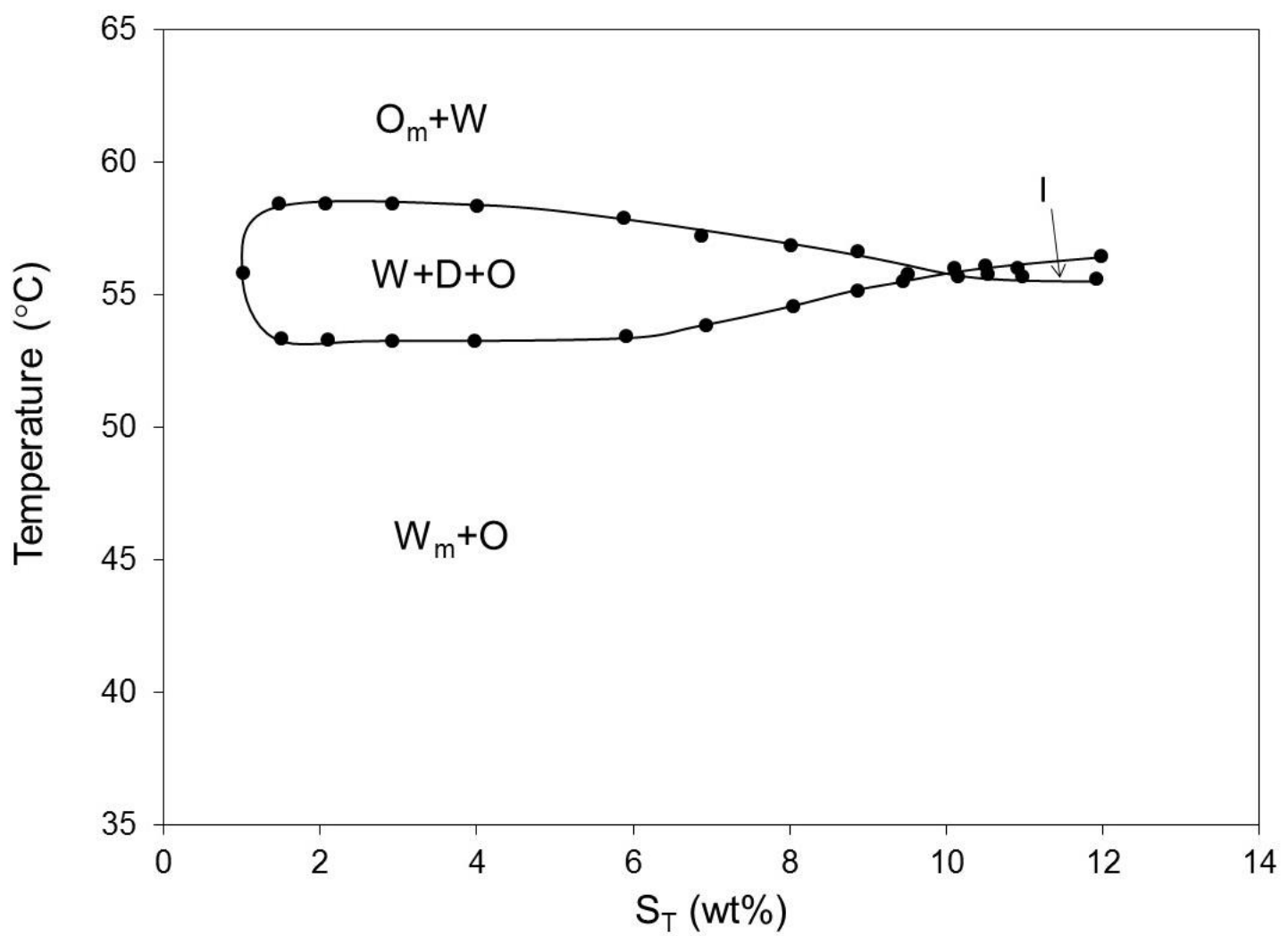

Figure 2: Phase diagram of the water $/ \mathrm{C}_{12} \mathrm{E}_{6} /$ decane system at constant water/decane (W/O) ratio of 50/50 as a function of temperature and total surfactant concentration $\left(\mathrm{S}_{\mathrm{T}}\right)$. $\mathrm{W}$ : Aqueous phase; $\mathrm{W}_{\mathrm{m}}$ : direct $\mathrm{O} / \mathrm{W}$ microemulsion phase; O: oil phase; $\mathrm{O}_{\mathrm{m}}$ : Reverse W/O microemulsion phase; D: Bicontinuous microemulsion phase (D). I is an isotropic, single-phase region. Adapted with permission from Ref.80 


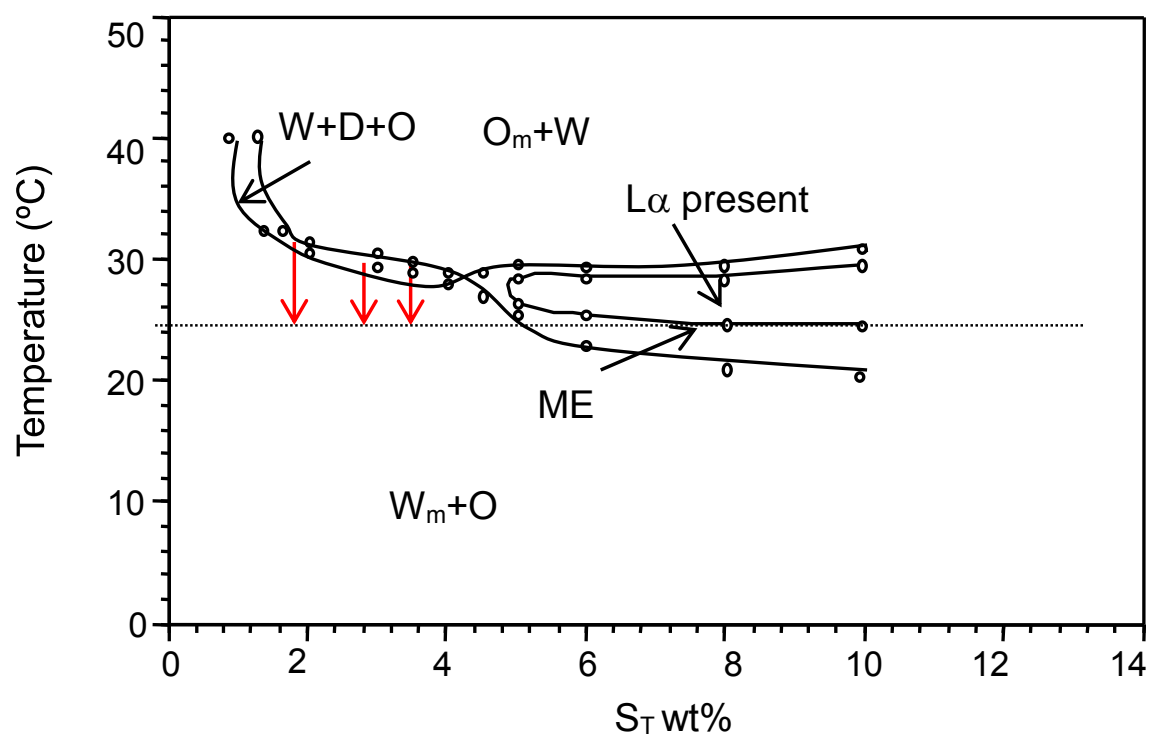

Figure 3. Phase diagram of the water/ $\mathrm{C}_{16} \mathrm{E}_{4}+\mathrm{C}_{12} \mathrm{E}_{6} /$ decane system at constant water/decane (W/O) weight ratio of $80 / 20$ as a function of temperature and total surfactant concentration $\left(\mathrm{S}_{\mathrm{T}}\right)$. W: Aqueous phase; $\mathrm{W}_{\mathrm{m}}$ : direct $\mathrm{O} / \mathrm{W}$ microemulsion phase; O: oil phase; $\mathrm{O}_{\mathrm{m}}$ : Reverse W/O microemulsion phase; ME: microemulsion phase, L $\alpha$ : Lamellar Liquid Crystalline phase. The red arrows indicate the emulsification path. Feng and Solans, unpublished results. 


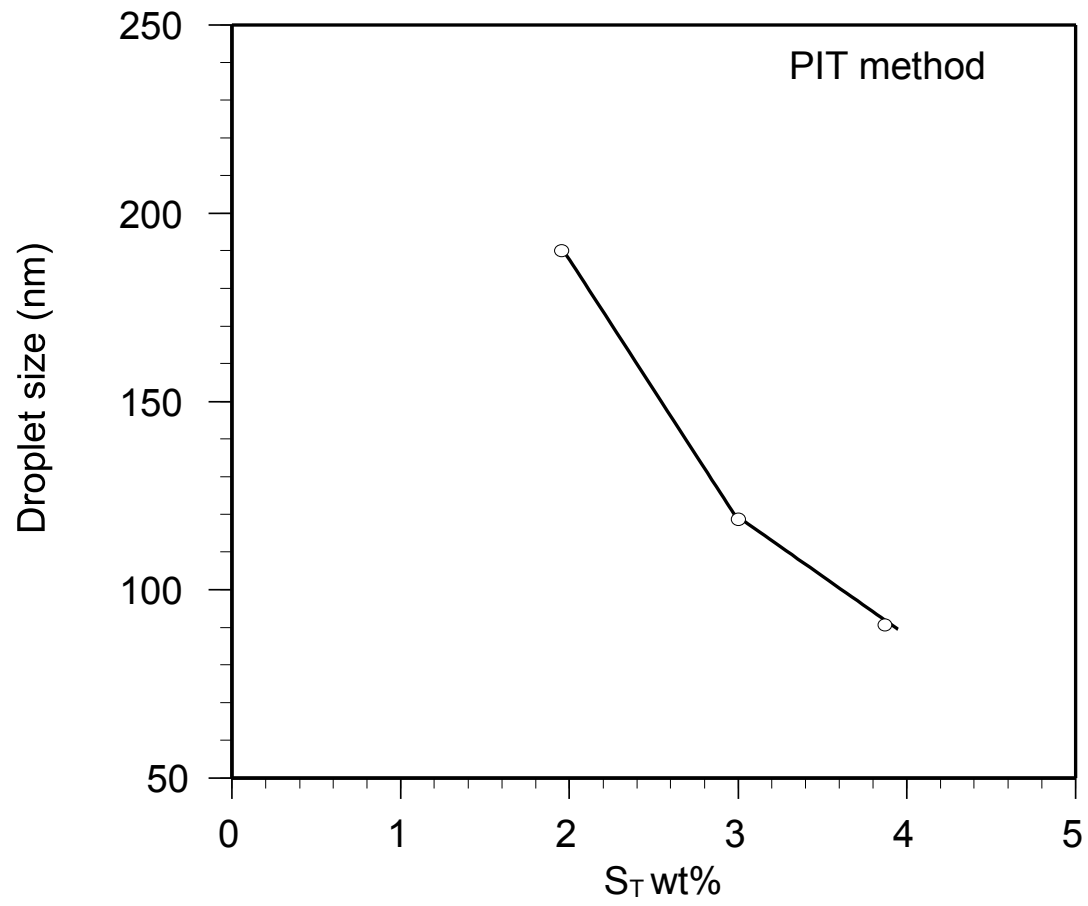

Figure 4. Droplet size of nano-emulsions (at $25^{\circ} \mathrm{C}$ ) of the water/ $\mathrm{C}_{16} \mathrm{E}_{4}+\mathrm{C}_{12} \mathrm{E}_{6} /$ decane system at constant water/decane (W/O) weight ratio of 80/20, obtained by the PIT method as a function of the total surfactant concentration $\left(\mathrm{S}_{\mathrm{T}}\right)$. Feng and Solans, unpublished results. The polydispersity index is below 0.2 . 


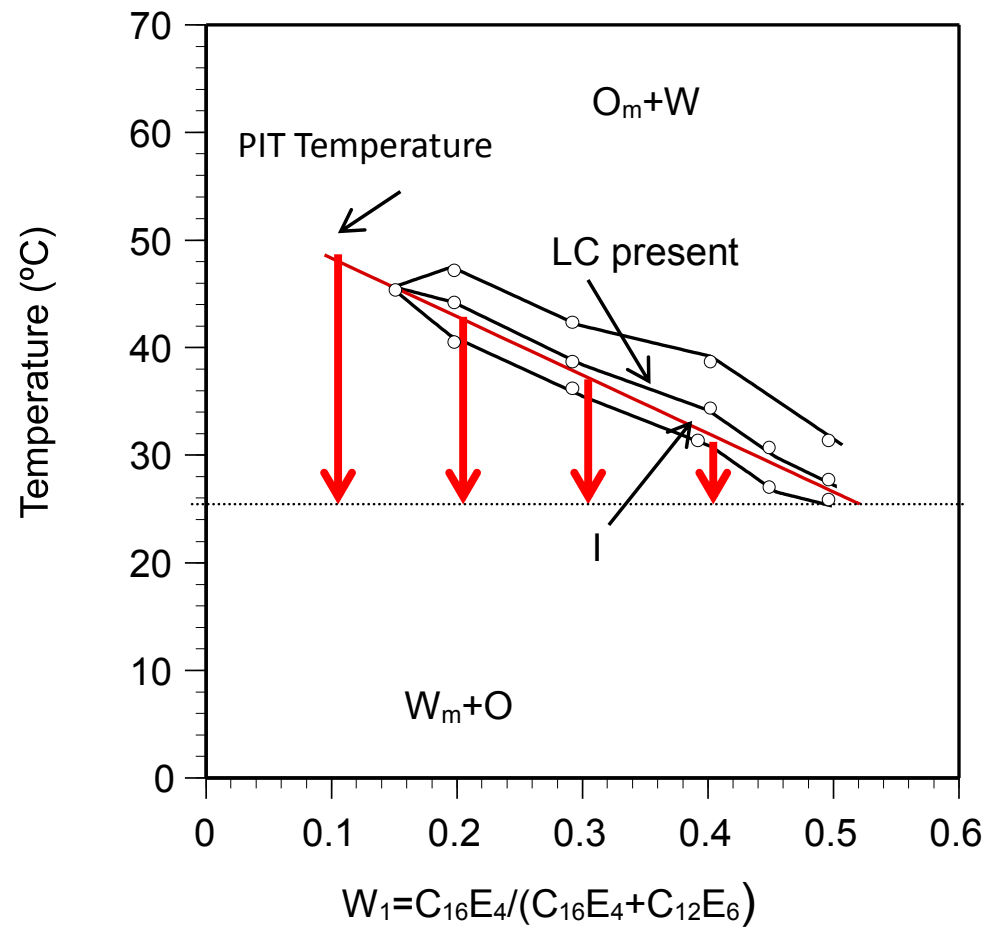

Figure 5. Phase diagram of the water/ $\mathrm{C}_{16} \mathrm{E}_{4}+\mathrm{C}_{12} \mathrm{E}_{6} /$ decane system at constant water/decane (W/O) weight ratio of $80 / 20$ and total surfactant concentration of $5 \%$, as a function of temperature and surfactant mixing ratio $\left(\mathrm{W}_{1}\right)$. LC: liquid crystal phase. I: isotropic, single-phase region. Feng and Solans, unpublished results. 


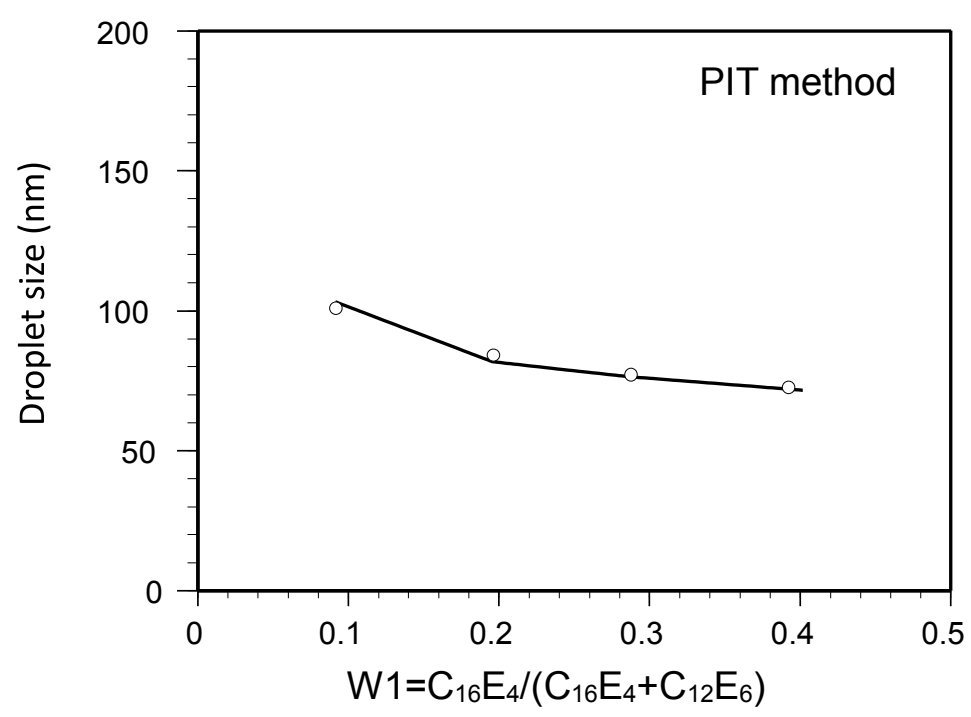

Figure 6. Droplet size of nano-emulsions (at $25^{\circ} \mathrm{C}$ ) obtained by cooling samples from the corresponding PIT to $25^{\circ} \mathrm{C}$ (indicated by arrows in Figure 3) as a function of $\mathrm{W}_{1}$. Water/decane $(\mathrm{W} / \mathrm{O})$ weight ratio $=80 / 20$. Total surfactant concentration $=5 \%$. Feng and Solans, unpublished results. The polydispersity index is below 0.2. 

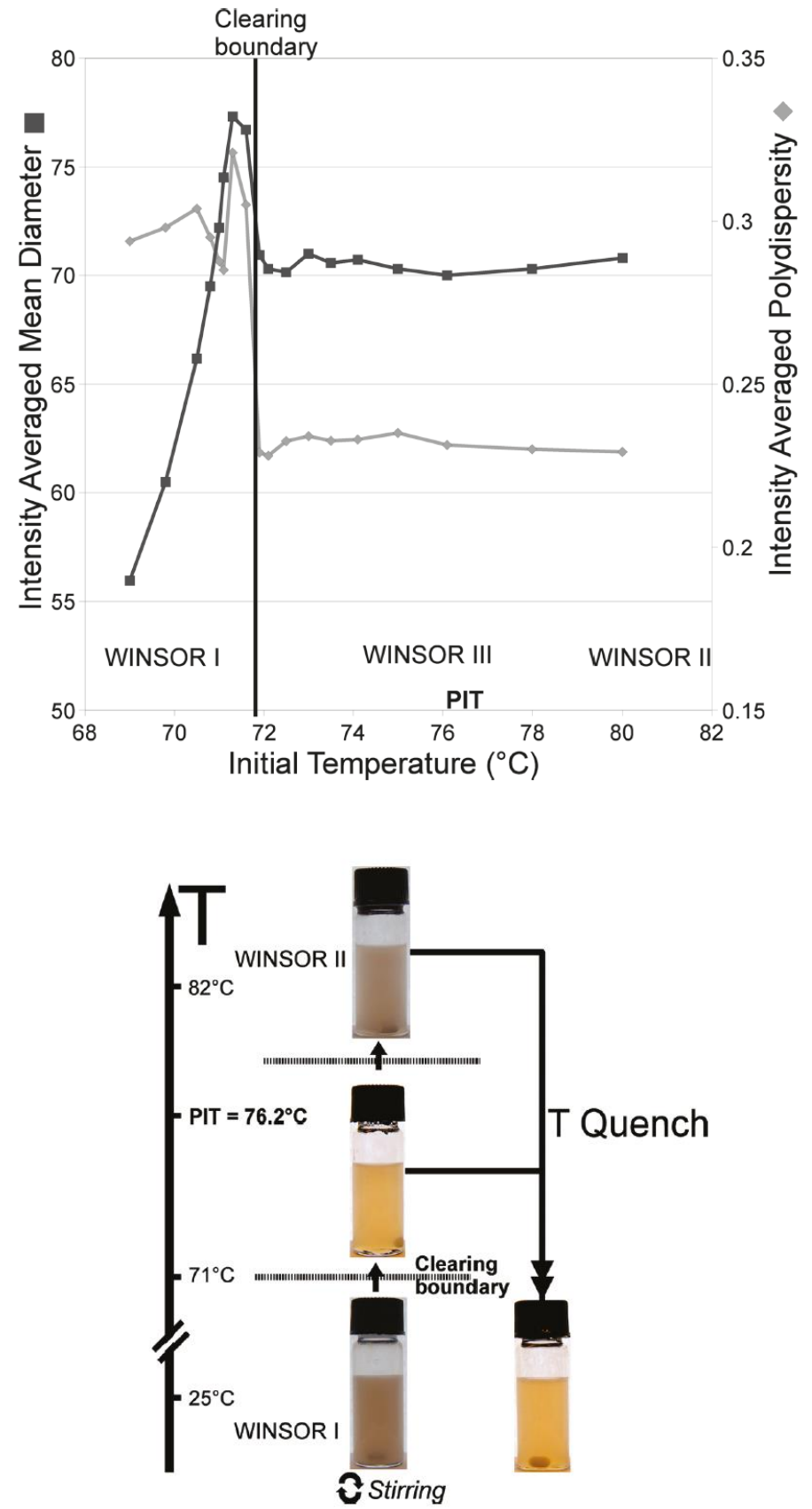

Figure 7 Mean size and polydispersity (top) and appearance (bottom) of emulsions in the $\mathrm{C}_{16} \mathrm{E}_{8} /$ hexadecane/water system. The emulsions are stir-quenched from different initial temperatures to $25^{\circ} \mathrm{C}$. The PIT of the system is $76.2{ }^{\circ} \mathrm{C}$. Water/oil $(\mathrm{W} / \mathrm{O})$ ratio $=0.2$, oil/surfactant mass ratio=3.5. For initial temperatures below the clearing boundary, a bimodal distribution is obtained after the quench, whereas for initial temperatures above the clearing boundary a unimodal distribution is obtained after quenching. Winsor I, Winsor III and Winsor II are equivalent to $\mathrm{W}_{\mathrm{m}}+\mathrm{O}, \mathrm{W}+\mathrm{D}+\mathrm{O}$, and $\mathrm{O}_{\mathrm{m}}+\mathrm{W}$, respectively, according to the nomenclature of Figure 1. Reproduced with permission from Ref.52 


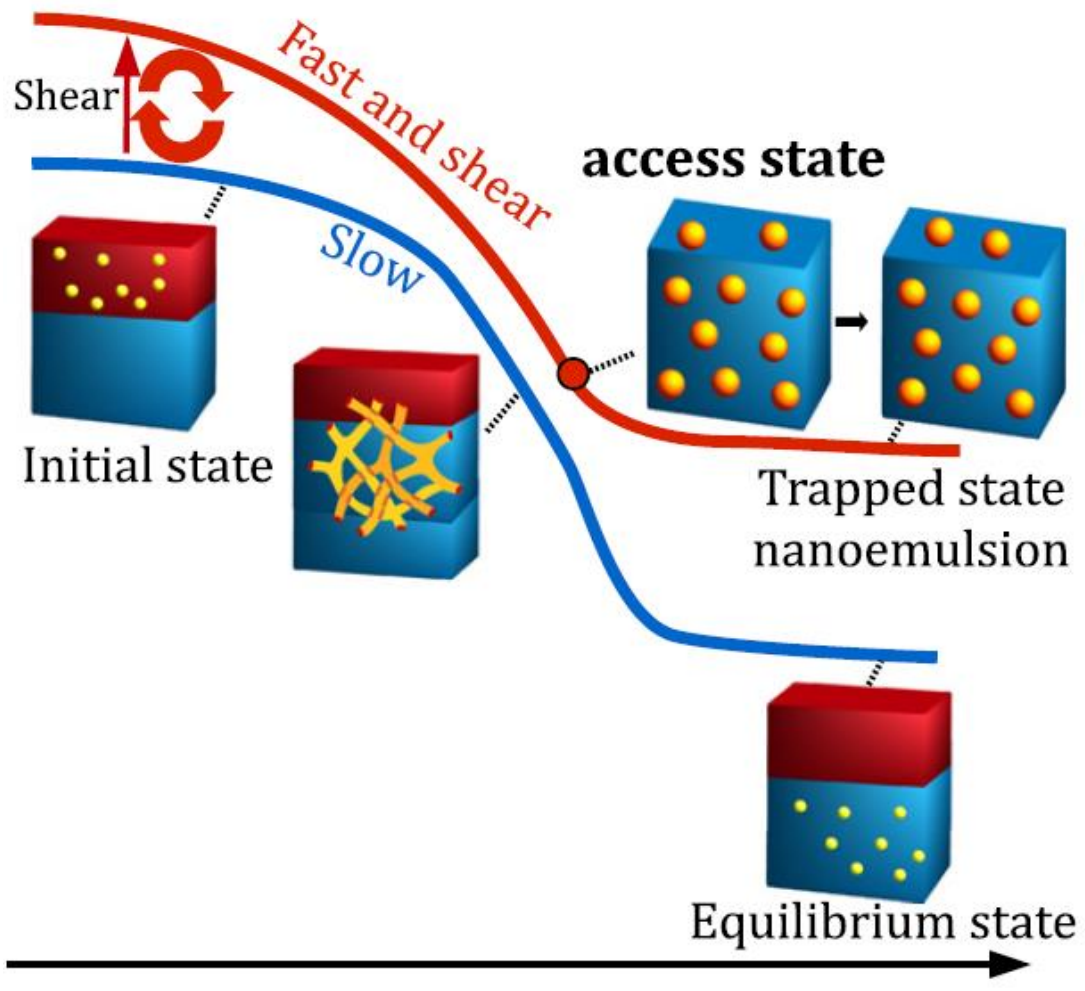

Figure 8. Proposed scheme of the nano-emulsification through a "superswelled access state" by the sub-PIT method. O/W nano-emulsions are formed by a fast decrease of temperature while simultaneously applying agitation (red upper curve). Initial temperature is selected to achieve a disruption of the bicontinuous nanostructure, forming a transient swelled microemulsion (access state) that forms the final trapped state nanoemulsion. In contrast, nano-emulsions are not formed when temperature is slowly reduced in absence of shear (blue lower curve), leading to separated phases at the equilibrium state. Reproduced from Ref. 77, with permission 